\title{
Effect of tracheal lidocaine on intubating conditions during propofol-remifentanil target-controlled infusion without neuromuscular blockade in day-case anesthesia
}

\author{
Jin-Soo Kim, Dae-Hee Kim, Han Bum Joe, Chang Keun Oh, and Jong-Yeop Kim \\ Department of Anesthesiology and Pain Medicine, Ajou University School of Medicine, Suwon, Korea
}

Background: Lidocaine is a useful intravenous and topical adjunct to facilitate tracheal intubation. We evaluated the effect of tracheal lidocaine on tracheal intubating conditions without neuromuscular blocking agent and hemodynamics during anesthesia induction with propofol and remifentanil target-controlled infusion (TCI).

Methods: Fifty patients, aged 18-60 years, scheduled for closed reduction of fractured nasal bone were randomly assigned to the control group $(n=25)$ or lidocaine group $(n=25)$. Anesthesia was induced with propofol-remifentanil TCI with the effect-site concentration of $5 \mu \mathrm{g} / \mathrm{ml}$ and $5 \mathrm{ng} / \mathrm{ml}$. Four minutes after the start of propofol-remifentanil TCI, $4 \%$ lidocaine or saline $3 \mathrm{ml}$ was instilled to larynx and trachea, and intubation was performed $1 \mathrm{~min}$ later. Acceptable intubation was defined as excellent or good intubating conditions. Hemodynamic data, induction and recovery profiles were recorded.

Results: Intubating condition was clinically acceptable in 13 out of 25 (52\%) patients in the control group and in 22 out of $25(88 \%)$ in the lidocaine group, and there was a significant difference between the two groups in regard to acceptable intubating conditions $(\mathrm{P}=0.005)$. Mean arterial pressure change over time was significantly different between the two groups. There were no significant differences in the heart rate between the two groups.

Conclusions: This study demonstrated that laryngotracheal administration of $4 \%$ lidocaine could increase the percentage of acceptable conditions for tracheal intubation during propofol and remifentanil anesthesia without neuromuscular blockade. (Korean J Anesthesiol 2013; 65: 425-430)

Key Words: Intravenous anesthesia, Intubation, Lidocaine.

\footnotetext{
Received: April 12, 2013. Revised: May 15, 2013. Accepted: May 21, 2013.

Corresponding author: Jong-Yeop Kim, M.D., Department of Anesthesiology and Pain Medicine, Ajou University School of Medicine, San 5, Woncheon-dong, Yeongtong-gu, Suwon 442-721, Korea. Tel: 82-31-219-5574, Fax: 82-31-219-5579, E-mail: kjyeop@ajou.ac.kr

(c) This is an open-access article distributed under the terms of the Creative Commons Attribution Non-Commercial License (http:// creativecommons.org/licenses/by-nc/3.0/), which permits unrestricted non-commercial use, distribution, and reproduction in any medium, provided the original work is properly cited.
} 


\section{Introduction}

A target-controlled infusion (TCI) of propofol has been used for day-case anesthesia, and it provides a smooth induction, good control of intraoperative condition, a rapid recovery and a low incidence of post-operative nausea and vomiting (PONV). In addition, co-administration of propofol and remifentanil has been shown to provide conditions for successful tracheal intubation without the use of a neuromuscular blocking drug [1-3]. Tracheal intubation without neuromuscular blocking drugs may be used in cases where tracheal intubation is necessary but prolonged muscle relaxation is not, such as in short ambulatory surgery. However, avoidance of neuromuscular blocking drugs may increase the risk of difficult tracheal intubation [4], and trauma to the airway can occur if laryngoscopy and intubation are attempted under unsuitable conditions (e.g., poor jaw relaxation, closed vocal cords).

When using propofol and remifentanil TCI without neuromuscular blockade for tracheal intubation, the main reason for rating failed intubation is coughing rather than unfavorable vocal cord or laryngoscopic scores [3]. This suggests that the primary stressor during tracheal intubation is the trachea stimulus $[5,6]$. However, relatively higher anesthetic concentrations to obtund airway reflexes for tracheal intubation inevitably produce adverse hemodynamic events [7,8]. Laryngotracheal lidocaine could attenuate cardiovascular responses to endotracheal intubation [9], and improve intubating conditions without muscle relaxants [10]. In addition, total intravenous anesthesia (TIVA), in contrast to volatile anesthesia, has the advantage of maintaining steady anesthetic depth during the application of laryngotracheal lidocaine. In this randomized, double-blind study, we evaluated the effect of laryngotracheal lidocaine on the intubating conditions and hemodynamic responses for tracheal intubation during propofol and remifentanil TCI without neuromuscular blocking agent in day-case anesthesia.

\section{Materials and Methods}

This study was approved by the Institutional Review Board, and registered at ClinicalTrials.gov. Written informed consent for the study was obtained from all patients. We enrolled American Society of Anesthesiologists physical status I or II, aged 1860 years, undergoing day-case surgery for nasal bone fracture. Patients with a history of reactive airway disease, predicted difficult intubation (Mallampati class III-IV, history of difficult intubation), and obesity (body mass index $>30 \mathrm{~kg} / \mathrm{m}^{2}$ ) were excluded from the study. No premedication was administered prior to surgery. Upon arrival in the operating room, all patients were monitored with electrocardiogram, pulse oximeter, and noninvasive blood pressure and bispectral index (BIS) (BIS VISTA ${ }^{\mathrm{TM}}$ monitor, four electrode sensor; Aspect Medical Systems, Norwood, MA, USA). Using a computer generated randomization table, 50 patients were randomly assigned to the lidocaine group $(n=25)$ or control group $(n=25)$. Following injection of iv 0.2 mg glycopyrrolate, anesthesia was induced with propofol TCI at an effect-site concentration of $5.0 \mu \mathrm{g} / \mathrm{ml}$ and remifentanil TCI at an effect-site concentration of $5.0 \mathrm{ng} / \mathrm{ml}$, respectively, using a two-channel TCI pump (Orchestra ${ }^{\circledR}$, Fresenius Vial, Brezins, France). The pharmacokinetic sets used for calculation of target effect-site concentrations for propofol and remifentanil were Marsh et al. [11] and Minto et al. [12] models, respectively. Four minutes after induction, $4 \%$ lidocaine or normal saline $3 \mathrm{ml}$ was applied with a spray tip attached to $5 \mathrm{ml}$ syringe into the larynx $(1 \mathrm{ml})$ and trachea $(2 \mathrm{ml})$ under direct vision with a standard Macintosh laryngoscope. Tracheal intubation was performed 1 min after lidocaine instillation by an experienced anesthesiologist. Endotracheal tubes with an internal diameter of $7.0 \mathrm{~mm}$ were used for female patients and tubes with an internal diameter of $8.0 \mathrm{~mm}$ were used for male patients. Intubating conditions were evaluated according to a scoring system described by Fuchs-Buder et al. [13]: ease of laryngoscopy (Easy, Fair, Difficult), vocal cord position (Abducted, Intermediate/moving, Closed) and reaction to insertion of the tracheal tube and cuff inflation (diaphragmatic movement-coughing) (None, Slight; 1 to 2 weak contractions or movement for less than $5 \mathrm{~s}$, Vigorous; more than 2 contractions and/or movement for longer than $5 \mathrm{~s}$ ). Each of these variables was rated as excellent, good, or poor. Intubating conditions were excellent if all variables were excellent; they were good if at least one variable was good and the rest were excellent, and they were poor if any variable was poor. Acceptable intubation was defined as excellent or good intubating conditions. The anesthesiologist who performed the intubations and who assessed the intubating conditions was blinded regarding group assignment. If intubation failed, target concentration of propofol and remifentanil increased to 6 to 8 $\mu \mathrm{g} / \mathrm{ml}$ and 6 to $8 \mathrm{ng} / \mathrm{ml}$, respectively, and tracheal intubation was again attempted. Clinically significant hypotension and bradycardia during anesthesia induction were defined as a mean arterial pressure (MAP) of $<55 \mathrm{mmHg}$ and a heart rate (HR) of $<45$ beats/min, respectively. These conditions were treated with atropine or ephedrine where appropriate. At the end of surgery, propofol and remifentanil infusion stopped, and manual ventilation was begun with $100 \%$ oxygen. Extubation was performed in a standard manner when patients were able to open their eyes, squeeze a hand, and lift their head on command. Incidence of PONV and visual analogue scale (VAS; 0 for no pain, and 10 for the worst possible pain) were measured at $15 \mathrm{~min}$ after arrival in the post-anesthesia care unit (PACU). Postoperative pain was treated with iv $30 \mathrm{mg}$ ketorolac, if the VAS score was > 6 , or patients wanted analgesics. Patients were discharged from 
PACU after modified Aldrete score [14] of $\geq 9$ was noted. Hemodynamic data and BIS were recorded before induction, $2 \mathrm{~min}$ and $4 \mathrm{~min}$ after induction, and $2 \mathrm{~min}$ after intubation. Time to loss of consciousness (the interval between the start of TCI and loss of responsiveness to verbal command to open eyes every 10 s), operation time, anesthesia time, eye opening time (time from end of operation to eye opening), extubation time (time from end of operation to extubation), and coughing count at extubation were also measured.

Based on a previous study [7], we expected that the rate of clinically acceptable intubating conditions in the control group would be $35 \%$ which would improve to $80 \%$ with topical lidocaine. We needed 23 patients in each group to achieve $80 \%$ power and 5\% significance level. To allow for dropouts, we increased the sample size to 25 patients per group. Statistical analyses were performed using SPSS 13.0 for Windows (SPSS Inc., Chicago, IL, USA). Data are expressed as mean \pm SD or number of patients. Patient characteristics and induction, recovery profiles were compared using Student's t-test. Categorical data were analyzed using chi-square test. Changes in hemodynamic data over time between the groups were compared by repeated measures ANOVA. A $P$ value $<0.05$ was considered significant.

Table 1. Patient Characteristics

\begin{tabular}{lcc}
\hline & $\begin{array}{c}\text { Control } \\
(\mathrm{n}=25)\end{array}$ & $\begin{array}{c}\text { Lidocaine } \\
(\mathrm{n}=25)\end{array}$ \\
\hline Age $(\mathrm{yr})$ & $29.2 \pm 11.5$ & $30.2 \pm 9.7$ \\
Sex $(\mathrm{M} / \mathrm{F})$ & $22 / 3$ & $20 / 5$ \\
Weight $(\mathrm{kg})$ & $67.5 \pm 8.8$ & $65.0 \pm 10.8$ \\
Height $(\mathrm{cm})$ & $172.0 \pm 6.9$ & $173.2 \pm 6.9$ \\
\hline
\end{tabular}

Values are mean \pm SD. No significant differences between the groups were noted.

Table 2. Induction and Recovery Profile

\begin{tabular}{lcc}
\hline & $\begin{array}{c}\text { Control } \\
(\mathrm{n}=25)\end{array}$ & $\begin{array}{c}\text { Lidocaine } \\
(\mathrm{n}=25)\end{array}$ \\
\hline LOC time (s) & $74.7 \pm 27.5$ & $67.0 \pm 22.9$ \\
Operation time (min) & $6.2 \pm 3.0$ & $6.0 \pm 3.2$ \\
Anesthesia time (min) & $32.9 \pm 7.0$ & $31.9 \pm 9.4$ \\
Eye opening time (min) & $7.9 \pm 3.0$ & $7.9 \pm 3.4$ \\
Extubation time (min) & $8.8 \pm 3.4$ & $8.7 \pm 3.4$ \\
Cough count after extubation & $0.9 \pm 1.0$ & $1.0 \pm 1.2$ \\
In PACU & & \\
$\quad$ PONV (n) & 1 & 2 \\
$\quad$ VAS & $2.7 \pm 1.2$ & $3.6 \pm 2.0$ \\
$\quad$ Patients given analgesics (n) & 2 & 4 \\
Staying time (min) & $30.4 \pm 2.0$ & $31.6 \pm 6.2$ \\
\hline
\end{tabular}

Values are mean \pm SD or number of patients. No significant differences between the groups were noted. LOC: loss of consciousness, PACU: post-anesthesia care unit, PONV: postoperative nausea and vomiting, VAS: visual analogue scale.

\section{Results}

A total of 56 patients were screened for eligibility, and $6 \mathrm{pa}-$ tients were excluded, leaving 50 patients to be randomized and complete the study. There were no significant differences in the patients' characteristics between the two groups (Table 1). There were no significant differences in the induction and recovery profiles between the two groups in the operating room and PACU (Table 2).

The overall intubating condition was regarded as clinically acceptable (excellent or good) in 13 out of $25(52 \%)$ patients in the control group and in 22 out of 25 (88\%) in lidocaine group, and there was a significant difference between two groups for acceptable intubating condition $(\mathrm{P}=0.005)$ (Table 3$)$. Intubating conditions were excellent in $6 / 25$ patients in the control group and $14 / 25$ patients in the lidocaine group $(\mathrm{P}=0.021)$. Intubating conditions were poor in $12 / 25$ and $3 / 25$ patients in the control and lidocaine groups, respectively $(\mathrm{P}=0.005)$. In the control group, the most common cause of poor intubating conditions was vigorous coughing.

Fig. 1 illustrates the changes in MAP and HR during induction of anesthesia. MAP change over time was significantly different between the two groups $(\mathrm{P}=0.033)$. MAP was significantly higher in the control group than in the lidocaine group immediately and $2 \mathrm{~min}$ after intubation. Compared with the baseline values (T0), MAP decreased significantly from $2 \mathrm{~min}$ after induction (T1) to 2 min after intubation (T4) in both groups. HR decreased significantly from $2 \mathrm{~min}$ after induction to 4 min after induction compared to the baseline value in both groups, and increased at immediately after intubation in the control group. There were no adverse respiratory events, such as laryngospasm, and $\mathrm{SpO}_{2}$ remained above $96 \%$ in all patients. One patient in each group was given ephedrine $4 \mathrm{mg}$ due to clinically significant hypotension. No significant difference was observed in BIS between the two groups during the study period

Table 3. Intubation Conditions and Causes of Unacceptable Intubating Condition

\begin{tabular}{lcc}
\hline & $\begin{array}{c}\text { Control } \\
(\mathrm{n}=25)\end{array}$ & $\begin{array}{c}\text { Lidocaine } \\
(\mathrm{n}=25)\end{array}$ \\
\hline Acceptable & 13 & $22^{*}$ \\
$\quad$ Overall & 6 & $14^{*}$ \\
$\quad$ Excellent & 7 & 8 \\
$\quad$ Good & 12 & 3 \\
$\quad$ Unacceptable & & \\
$\quad$ Poor & & \\
Cause of unacceptable intubating condition & 4 & 1 \\
$\quad$ Difficult laryngoscopy & 6 & 2 \\
$\quad$ Closed vocal cord & 12 & $3 *$ \\
$\quad$ Vigorous coughing & &
\end{tabular}

Values are number of patients. ${ }^{*} \mathrm{P}<0.05$, vs. control group. 
A

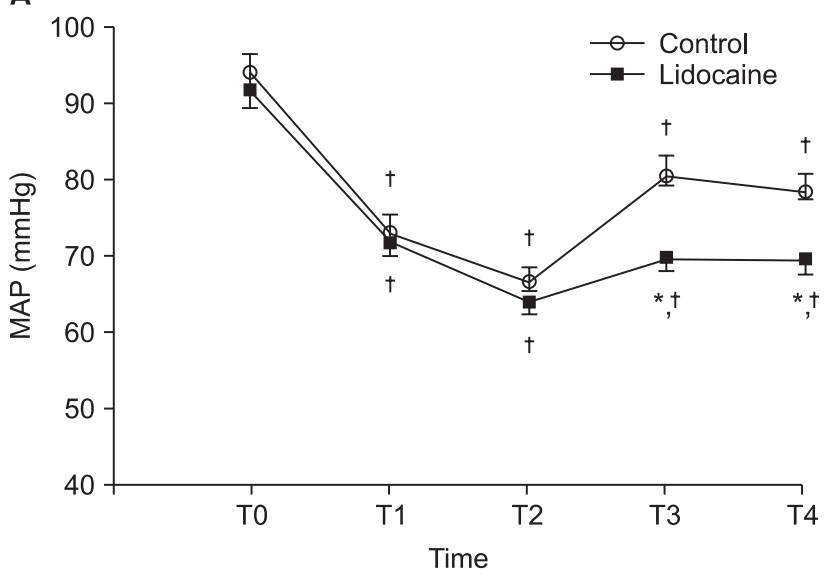

B

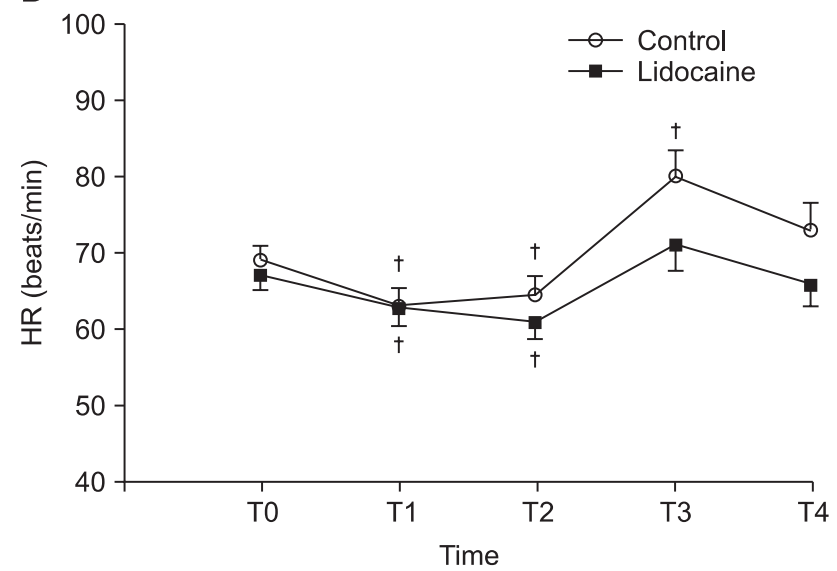

Fig. 1. (A) The changes in mean arterial pressure (MAP) and (B) heart rate (HR) during anesthesia induction. Error bar means standard error. T0: before anesthesia induction, T1: $2 \mathrm{~min}$ after induction, T2: $4 \mathrm{~min}$ after induction, T3: immediately after tracheal intubation, T4: 2 min after tracheal intubation. ${ }^{*} \mathrm{P}<0.05$ vs. control group. ${ }^{\dagger} \mathrm{P}<0.05$ vs. T0 within the group.

(data not shown). At 4 min after anesthesia induction, mean \pm SD of BIS was $53 \pm 13$ and $51 \pm 9$ in the control and lidocaine groups, respectively, and there was no significant difference $(\mathrm{P}=$ 0.49 ).

\section{Discussion}

This study demonstrated that laryngotracheal administration of $4 \%$ lidocaine could achieve better intubation conditions in day-case anesthesia using propofol and remifentanil without a neuromuscular blocking agent, and attenuate the pressor response to tracheal intubation.

Propofol and remifentanil have several properties, which make them potentially useful as day-case anesthetics. The use of TIVA with propofol and remifentanil resulted in significantly fewer episodes of PONV compared with sevoflurane, and was associated with earlier awakening in day-case anesthesia [15]. However, because high concentration of remifentanil or propofol TCI to obtund airway reflexes for tracheal intubation is related to frequent hypotension and bradycardia requiring treatment [16] or delayed awakening, laryngotracheal lidocaine spray was chosen for cough suppression in this study. Previous study by Bülow et al. [10] showed that, when compared with saline spray, laryngotracheal lidocaine spray of $160 \mathrm{mg}$ provided satisfactory intubating conditions from 73 to $100 \%$ during anesthesia induction using propofol $2.5 \mathrm{mg} / \mathrm{kg}$ and alfentanil $30 \mu \mathrm{g} / \mathrm{kg}$ without muscle relaxants. Our study showed that the administration of lidocaine $120 \mathrm{mg}$ into larynx and trachea during propofol-remifentanil TCI improved acceptable intubating conditions from 52 to $88 \%$ in adult patients without hemodynamic perturbations. In addition, the proportion of excellent intubating conditions was greater in the lidocaine group than in the control group. The major cause of unacceptable intubation condition was coughing in the control group. This was consistent with earlier studies evaluating intubating conditions without neuromuscular blockade during propofol-remifentanil TCI $[3,16]$.

In this study, it is likely that cough suppression by tracheal lidocaine resulted from local effects. Hamaya and Dohi [17] suggested that the inhibition of airway tactile stimulation with topical lidocaine could be mainly due to direct blockade of the mechanoreceptors of the airways and partly to its systemic effect. In addition, they found that the peak serum lidocaine concentration is at 5 to $10 \mathrm{~min}$ after laryngeal application of $200 \mathrm{mg}$ lidocaine [17]. Since we used a lidocaine dose of $120 \mathrm{mg}$ and the interval $60 \mathrm{~s}$ is shorter than that to peak concentration, the systemic effect of lidocaine is either small or negligible. Therefore, the probable reason for improvement in the intubation conditions seems to be the local, not the systemic, anesthetic effect of lidocaine. Intravenous lidocaine has been reported to be a useful adjunct to suppress the cough reflex during tracheal intubation without neuromuscular blockade. Yukioka et al. [18] note that intravenous administration of lidocaine $2 \mathrm{mg} / \mathrm{kg}$ at $1 \mathrm{~min}$ before intubation completely suppressed cough reflex. However, though no patient with lidocaine side effects was noted in their study, the authors conclude that this dose may produce systemic toxicity, because some patients showed high blood concentration of $8 \mu \mathrm{g} / \mathrm{kg}$.

Several studies have examined the efficacy of tracheal lidocaine in attenuating the hemodynamic responses to endotracheal intubation $[9,19,20]$, with inconsistent results, depending on the timing of lidocaine administration. Tracheal administration of lidocaine $1 \mathrm{~min}$ before tracheal intubation was ineffective for attenuation of the cardiovascular response to intubation $[19,20]$. However, tracheal lidocaine attenuated pressor responses to in- 
tubation when the tracheal intubation was performed more than 2 min after a tracheal spray in a study by Takita et al. [9]. They suggested that sufficient time is needed for tracheal lidocaine to attenuate the hemodynamic responses to laryngoscopy and intubation. In our study, tracheal lidocaine spray 1 min before tracheal intubation was performed could reduce, but not abolish the pressor response to tracheal intubation during propofolremifentanil TCI.

There are some limitations in this study. First, percentage of acceptable intubating conditions in the control group was low, only $52 \%$, probably due to shallow depth of anesthesia. However, although the higher effect-site concentration of remifentanil could increase the acceptable intubation condition rate of the control group, its higher doses would have been implicated in hemodynamic instability and chest wall rigidity before tracheal intubation during propofol induction. Previous studies reported significant decreases in MAP and HR before intubation during propofol induction in combination with the higher doses of remifentanil without neuromuscular blockade $[7,21]$. Second, we did not confirm that the improvement in intubating conditions by laryngotracheal lidocaine spray would reduce postoperative laryngeal morbidity, because postoperative laryngeal sequelae were not evaluated in this study. However, better intubating condition has been reported to be associated with lower incidence of postoperative hoarseness and vocal cord injuries [22]. Further studies exploring the association between lidocaine spray and laryngeal morbidity might be needed.

In conclusion, in day-case anesthesia, laryngotracheal administration of lidocaine is an effective method for neuromuscular blocking agent-free tracheal intubation during propofol remifentanil TCI without increasing the risk of hypotension during anesthesia induction.

\section{References}

1. Alexander R, Olufolabi AJ, Booth J, El-Moalem HE, Glass PS. Dosing study of remifentanil and propofol for tracheal intubation without the use of muscle relaxants. Anaesthesia 1999; 54: 1037-40.

2. Woods AW, Grant S, Harten J, Noble JS, Davidson JA. Tracheal intubating conditions after induction with propofol, remifentanil and lignocaine. Eur J Anaesthesiol 1998; 15: 714-8.

3. Ithnin F, Lim Y, Shah M, Shen L, Sia AT. Tracheal intubating conditions using propofol and remifentanil target-controlled infusion: a comparison of remifentanil EC50 for Glidescope and Macintosh. Eur J Anaesthesiol 2009; 26: 223-8.

4. Lundstrøm LH, Møller AM, Rosenstock C, Astrup G, Gätke MR, Wetterslev J. Avoidance of neuromuscular blocking agents may increase the risk of difficult tracheal intubation: a cohort study of 103,812 consecutive adult patients recorded in the Danish Anesthesia Database. Br J Anaesth 2009; 103: 283-90.

5. Takahashi S, Mizutani T, Miyabe M, Toyooka H. Hemodynamic responses to tracheal intubation with laryngoscope versus lightwand intubating device (Trachlight) in adults with normal airway. Anesth Analg 2002; 95: 480-4.

6. Hirabayashi Y, Hiruta M, Kawakami T, Inoue S, Fukuda H, Saitoh K, et al. Effects of lightwand (Trachlight) compared with direct laryngoscopy on circulatory responses to tracheal intubation. Br J Anaesth 1998; 81: 253-5.

7. Stevens JB, Wheatley L. Tracheal intubation in ambulatory surgery patients: using remifentanil and propofol without muscle relaxants. Anesth Analg 1998; 86: 45-9.

8. Troy AM, Huthinson RC, Easy WR, Kenney GN. Tracheal intubating conditions using propofol and remifentanil target-controlled infusions. Anaesthesia 2002; 57: 1204-7.

9. Takita K, Morimoto Y, Kemmotsu O. Tracheal lidocaine attenuates the cardiovascular response to endotracheal intubation. Can J Anaesth 2001; 48: 732-6.

10. Bülow K, Nielsen TG, Lund J. The effect of topical lignocaine on intubating conditions after propofol-alfentanil induction. Acta Anaesthesiol Scand 1996; 40: 752-6.

11. Marsh B, White M, Morton N, Kenny GN. Pharmacokinetic model driven infusion of propofol in children. Br J Anaesth 1991; 67: 41-8.

12. Minto CF, Schnider TW, Egan TD, Youngs E, Lemmens HJ, Gambus PL, et al. Influence of age and gender on the pharmacokinetics and pharmacodynamics of remifentanil. I. Model development. Anesthesiology 1997; 86: 10-23.

13. Fuchs-Buder T, Claudius C, Skovgaard LT, Eriksson LI, Mirakhur RK, Viby-Mogensen J. Good clinical research practice in pharmacodynamic studies of neuromuscular blocking agents II: the Stockholm revision. Acta Anaesthesiol Scand 2007; 51: 789-808.

14. Aldrete JA. The post-anesthesia recovery score revisited. J Clin Anesth 1995; 7: 89-91.

15. Hong JY, Kang YS, Kil HK. Anaesthesia for day case excisional breast biopsy: propofol-remifentanil compared with sevoflurane-nitrous oxide. Eur J Anaesthesiol 2008; 25: 460-7.

16. Kim SJ, Yoo KY, Park BY, Kim WM, Jeong CW. Comparison of intubating conditions and hemodynamic responses to tracheal intubation with different effect-site concentrations of remifentanil without muscle relaxants during target-controlled infusion of propofol. Korean J Anesthesiol 2009; 57: 13-9.

17. Hamaya Y, Dohi S. Differences in cardiovascular response to airway stimulation at different sites and blockade of the responses by lidocaine. Anesthesiology 2000; 93: 95-103. 
18. Yukioka H, Yoshimoto N, Nishimura K, Fujimori M. Intravenous lidocaine as a suppressant of coughing during tracheal intubation. Anesth Analg 1985; 64: 1189-92.

19. Mostafa SM, Murthy BV, Barrett PJ, McHugh P. Comparison of the effects of topical lignocaine spray applied before or after induction of anaesthesia on the pressor response to direct laryngoscopy and intubation. Eur J Anaesthesiol 1999; 16: 7-10.

20. Derbyshire DR, Smith G, Achola KJ. Effect of topical lignocaine on the sympathodrenal responses to tracheal intubation. Br J Anaesth 1987; 59: 300-4.

21. Klemola UM, Mennander S, Saarnivaara L. Tracheal intubation without the use of muscle relaxants: remifentanil or alfentanil in combination with propofol. Acta Anaesthesiol Scand 2000; 44: 465-9.

22. Mencke T, Echternach M, Kleinschmidt S, Lux P, Barth V, Plinkert PK, et al. Laryngeal morbidity and quality of tracheal intubation: a randomized controlled trial. Anesthesiology 2003; 98: 1049-56. 